\title{
Publicly Private and Privately Public: Social Networking on YouTube
}

\author{
Patricia G. Lange \\ School of Cinematic Arts \\ University of Southern California
}

\begin{abstract}
YouTube is a public video-sharing website where people can experience varying degrees of engagement with videos, ranging from casual viewing to sharing videos in order to maintain social relationships. Based on a one-year ethnographic project, this article analyzes how YouTube participants developed and maintained social networks by manipulating physical and interpretive access to their videos. The analysis reveals how circulating and sharing videos reflects different social relationships among youth. It also identifies varying degrees of "publicness" in video sharing. Some participants exhibited "publicly private" behavior, in which video makers' identities were revealed, but content was relatively private because it was not widely accessed. In contrast, "privately public" behavior involved sharing widely accessible content with many viewers, while limiting access to detailed information about video producers' identities.
\end{abstract}

doi:10.1111/j.1083-6101.2007.00400.x

\section{Introduction}

As social network sites (SNS) gain users and visibility, a wide range of websites have adopted SNS features (boyd \& Ellison, this issue). YouTube began as a video sharing platform, but it also offers users a personal profile page-which YouTube calls a "channel page" - and enables "friending." Research on SNSs has shown that the meanings of social network site practices and features differ across sites and individuals (boyd, 2006). This article explores how YouTube users employ the technical and social affordances of the site to calibrate access to their videos by members of their social circle. Specifically, it examines how video sharing can support social networks by facilitating socialization among dispersed friends. An important goal of the article is to document how youth and young adults use YouTube's video sharing and commenting features to project identities that affiliate with particular social groups. The analysis also evaluates to what extent YouTube's video sharing practices are conducted in public view (versus as private video exchanges) and how these choices reflect different kinds of social relationships. For example, how does sharing videos with certain friends but not others reflect different kinds of friendships? More generally, how do young people maintain and delineate distinct social networks through public video sharing? 
In order to address these questions and themes, I begin by describing theoretical frameworks that illustrate the relationship between media exchange and the processes whereby social networks are negotiated online and in public. I then discuss how youth and young adults manipulate both technical features and social mechanisms to achieve different levels of visibility in their media sharing activities. Using a combination of ethnographic methods that included semi-structured, formal interviews and analyses of videos, comments, and video responses, I argue that "friendship linkages" are not the only-or even the primary-way in which some participants express social linkages. Furthermore, I suggest that YouTube participation involves more than strictly public or private interaction. Through an examination of two categories that complicate this dichotomy- "publicly private" and "privately public" behavior-this article describes how participants manipulate media to maintain social networks and intimacy amid public scrutiny. It is shown that expectations about what should be shared or withheld on YouTube vary considerably according to individual needs and according to different types of social relationships.

\section{Background}

The concept of "social networks" is difficult to define. Wellman (1996) argues that online and offline social networks do not exist as such, but that they are useful analytic constructs for understanding social dynamics. A social network will look different depending upon how one measures it (counting the number of interactions between members versus rating the closeness of relationships, for instance). A social network is defined here as relations among people who deem other network members to be important or relevant to them in some way (Wellman, 1996). Using media to develop and maintain social networks is an established practice (Baym, 2000; Horst \& Miller, 2006; Ito \& Okabe, 2005; Kendall, 2002).

One way that social networks are articulated and negotiated on social network sites is through linking and viewing profiles (Donath \& boyd, 2004; Gross \& Acquisti, 2005). The linking of profiles through friendship requests and acceptances and the ability to view the resulting connections on others' profiles are tangible mechanisms that reflect existing social networks. They also reflect change, as when friends are added (Ellison, Steinfield, \& Lampe, 2007). By studying social and technical choices that participants make on social network sites, it is possible to analyze how different social networks are created, maintained, and negotiated through media (Ellison et al., 2007; Gross \& Acquisti, 2005).

Social network sites are defined as websites that allow participants to construct a public or semi-public profile within the system and that formally articulate their relationship to other users in a way that is visible to anyone who can access their profile (boyd \& Ellison, this issue). This definition does not specify the closeness of any given connection, but only that participants are linked in some fashion. Similarly, this article considers social networks in a broad sense and examines their 
sub-instantiations as they are visibly reflected on YouTube through friending practices, video sharing, and posting comments to videos.

\section{Maintaining Social Networks Through Media Circuits}

Writing about transnational migration, Rouse (1991) proposed a useful framework for understanding the role of media in social network maintenance. He analyzed how Mexican immigrants used media to stay in touch, engage in community decisionmaking, and "participate in familial events even from a considerable distance" (p. 13). The telephone was not used merely to maintain contact; it also helped immigrants engage intensely with distant loved ones and friends. The use of media by members of a social group to stay connected or to interact with other members of the group constitutes a "media circuit." In Rouse's example, the media circuit connected people via the telephone. Media circuits in other forms-such as interconnections through video sharing-may also be examined to understand the social dynamics of a particular group. A media circuit is not a social network itself, but rather it supports social networks by facilitating and technically mediating social interactions among people within a network.

By examining a media circuit, it is possible to understand important social dynamics among the people who use the media. On YouTube, for example, a person may make and share certain kinds of videos with one set of friends, while making and sharing other types of videos with a different set of friends. Although it is not feasible to obtain information about all the media that are exchanged across a social network, Rouse's framework provides a window into particular instantiations of a social network as tangibly reflected in related media use. A media circuit helps some members of a social group to stay connected or interact in qualitatively meaningful ways. Not all members of a social group may participate in a particular media circuit, but examining media use reveals crucial aspects of relationships among participants. In the context of video sharing, posting videos that are shared with certain individuals and not others materially reflects different social configurations.

People who do not regularly participate on YouTube may not understand why people watch seemingly poor quality or odd videos on the site. Yet those videos may serve important social functions, and their utility is not necessarily judged by technical criteria. Media utility is often assessed in terms of the bandwidth or quality of information that a particular medium affords (Nardi, 2005). However, in the context of instant messaging, Nardi (2005) demonstrates how certain exchanges are not focused on information gathering. Rather they strive to establish an "affinity," which Nardi defines as a "feeling of connection" between people who "[experience] an openness to interacting with another person" (p. 92). Evaluating an instant message in terms of novel information ignores how short, similarly worded messages may transmit feelings of openness and affinity to the people to whom they are circulated. How and why media like instant messages or videos are viewed, enjoyed, and forwarded reveal much about the participants and their relationships. How they are shared also provides insight into distinctions between public and private. 


\section{Interrogating the Public/Private Dichotomy}

Scholars invoking the public/private dichotomy typically use one of two analytically distinct metaphors (Weintraub, 1997). The first is "what is hidden or withdrawn versus what is open, revealed, or accessible" (pp. 4-5). Private things are "things that we are able and/or entitled to keep hidden, sheltered, or withdrawn from others" (p. 6). Similarly, "individuals have privacy to the extent that others have limited access to information about them, to the intimacies of their lives, to their thoughts or bodies" (Sheehan, 2002, p. 22). This includes preventing physical access to materials, as well as using symbols that are not easily understood by people outside a small social group. Intent, however, does not guarantee success, which depends upon the capabilities of interpreting parties, who may detect someone's identity or decipher arcane meanings in videos. The second line of analysis used to distinguish between the public and private concerns "what is individual, or pertains only to an individual, versus what is collective, or affects the interests of a collectivity" (Weintraub, 1997, pp. 4-5). This article analyzes the public and private both in terms of what is physically or symbolically more or less visible, and what counts as important or socially relevant for social network members. How "public" a video is can be evaluated according to both factors; it can be judged in terms of how much information a person yields about their identity and how much information in a video is accessed and meaningful to many people, as opposed to a select few.

Social and legal theorists have grappled with the subtleties of the public/private distinction. Nissenbaum (2004) introduces the concept of contextual integrity, which states that within a context of an interaction, people have expectations about what information is appropriate to collect and whether it should be distributed. For instance, when one friend tells another a secret, expectations within the context of "friendship" mean that a confidant will not widely distribute sensitive information. Nissenbaum stresses that ideas about contextual integrity vary across time, place, and culture. However, she does not account for variations within a particular context. On YouTube, people have different expectations about what information can be shared or what constitutes sensitive information. One useful lens for understanding differences in expectations about identity and content sharing within social networks is the concept of the fractalization of the public and private.

\section{The Fractalization of the Public and Private}

Some scholars suggest that communication technologies may be "eroding the boundaries between 'publicity' and 'privacy' in fundamental ways" (Weintraub \& Kumar, 1997, p. xi). At the same time, Weintraub and Kumar (1997) rightly assert that 'the enormous bodies of discourse that use 'public' and 'private' as organizing categories are not always informed by a careful consideration of the meanings and implications of the concepts themselves" (pp. xi-xii). Recent scholarship on the public/private distinction in mediated contexts confirms this observation. Several recent studies discussing public and private media do not acknowledge nuanced meanings. For instance, they 1) consider either visibility or social relevance to 
determine public/private boundaries, rather than incorporating both lenses (Barnes, 2006; Sandvig, 2006) or 2) do not consider how contexts other than the one they are analyzing shed light on public/private dimensions (Al-Saggaf, 2006). Such limitations are unsurprising, given that entire volumes grapple with these complex terms (Schoeman, 1984; Weintraub \& Kumar, 1997). Yet, nuances and gradations exist in who can access, manipulate, and distribute information. What do these nuances and gradations look like within different contexts? How do social and technical affordances enable or limit particular configurations? If communication technologies are eroding these boundaries, what are the social responses to this erosion?

Gal (2002) provides a useful lens for interrogating the meaning of and response to public/private erosions. According to Gal, "public" and "private" are relative terms and shift according to individual perspectives. The public/private dichotomy is thus more productively visualized as a "fractal distinction." A fractal is defined as "a shape made of parts similar to the whole in some way" (Feder, 1988). Gal explains, "Whatever the local, historically specific content of the dichotomy, the distinction between public and private can be reproduced repeatedly by projecting it onto narrower contexts or broader ones" (p. 81). For instance, a home is private when contrasted with the neighborhood. At the same time, public and private spaces exist within the home. At a higher level, community matters may appear private relative to affairs at the level of state government.

Examining the fractalized patterns of public and private video access and interpretation reveals different social networks and their dynamics within the context of public video sharing. Just as small towns constitute a socio-spatial domain that subdivides when smaller social networks require neighborhood interaction, so, too, do video-sharing practices sub-divide in ways that reflect different social networks and relationship dynamics. Studying the fractalization of video-sharing practices thus provides a valuable lens through which to view how social relations shift and subdivide within the context of visible media sharing.

\section{Method}

The analysis that follows is based on an ethnographic investigation into young people's engagement with online video sharing on YouTube. The data include semi-structured interviews, fieldnotes on observations conducted several times a week over the course of one year on YouTube, analyses of posted videos and comments, and examination of subscription and friending practices. ${ }^{1}$ The 54 interviewees ranged in age from 9 to 43 , although most were in the mid-teens to early 20s range. In keeping with the project's focus, most of the interviewees were from the United States, although two were from Canada and two were from Europe. Formal interviews lasted from one to three hours and included a pre-interview survey on interviewees' demographic background and media use. Twenty-nine interviews were conducted over the phone, 15 interviews were conducted via instant messaging chat, and 10 interviews were conducted face-to-face. 
Observations were collected during varied activities, including watching the main YouTube page to see what videos were featured, reading the YouTube video blog, watching videos of interviewees and others, reading video comments, and observing how YouTube participants responded to commentary (such as addressing a comment in a video). Other data include observations gathered at video-themed events that I attended in Los Angeles, San Francisco, and New York, including a YouTube meet-up on July 7, 2007 in New York City.

Interviewees were recruited in several ways, such as asking members of the research team's personal networks for interviews and sending email requests for interviews on the basis of YouTube content. Soliciting interviews from the researchers' social networks, such as acquaintances of project members, was helpful because several of these participants did not promote their videos widely on YouTube, if they posted videos at all. Such a strategy helped to illuminate a broader participation base than would have been possible by examining only youth who were popular or particularly visible on the site.

The interview protocol included questions about why the individuals participated on YouTube, how they responded to comments, and what they thought of certain issues on YouTube, such as how "haters" (people posting excessively negative commentary) should be dealt with (Lange, 2007). The interview items included questions such as:

- What are the major advantages and disadvantages about participating on YouTube? Are you a "YouTuber"? Why or why not?

- Do you know all the people who have posted comments to your videos? Where do you know them from (YouTube, elsewhere online, offline)? What were your reactions to the comments on your videos?

- Under what circumstances do you "friend" someone? Do you only make YouTube friends with people you know offline? Do you make YouTube friends with people only online or only from YouTube? Why? How do you decide to whom you will subscribe? How is the practice of "friending" someone on YouTube different from subscribing to their videos?

The interview was adapted to the interviewee's particular interests and background. Interviewees were also asked specific questions related to their media choices and interactions. For instance, interviewees who indicated that they had received text comments on their videos were asked if they knew specific people, either from online or offline contexts, who posted comments on their videos.

Interviewees represented a wide range of visibility, as indicated by the numbers of YouTube friends and viewers they had. Some were YouTube celebrities who uploaded dozens of videos, had thousands of friends and subscribers, and were recognized within the YouTube community and beyond. Others were not well known within YouTube, had few subscribers and friends, and posted few or no videos. 


\section{Results}

\section{Creating and Negotiating Social Networks Through Video Sharing}

Posting text comments and video responses to videos enacts Rouse's (1991) concept of media circuits that illustrates particular social network patterns. For example, an aunt of two boys that I interviewed posted a comment on one of their videos. Living several states away, the boys rarely see her. But by viewing her nephews' videos and posting comments, she re-affirms her position in a familial social network. When the boys read her posted comments, they complete a media circuit that began with an experience that was encoded in video, displayed, and commented upon by their aunt, who participated from afar. In this case, the media circuit helps maintain a social network that already exists. Media circuits take different forms and not only help maintain, but can also help create connections and negotiate relationship changes, as described below.

While some media circuits support existing social networks that began in-person, other social networks would not exist as such without online media circulation. For example, one YouTube celebrity expanded his network after posting videos for dispersed, unknown others to see. When a YouTube participant posts a video, viewers may "friend" the celebrity or comment on the video to garner the celebrity's attention. Several interviewees reported that an intelligent comment on their video usually prompted them to examine the commenter's work. In an environment where friending practices can become liberal, in that some participants routinely automatically accept friendship links, participants often post comments to increase their social visibility and connection to a video maker.

YouTube participants can broaden or limit physical access to their videos and thus create larger or smaller media circuits by using technical features such as limited "friends-only" viewing or strategic tagging. Viewers may locate videos using keywords or "tags" that video makers designate for their videos or write into the video's title or description. Given the limited capabilities of YouTube's search features at the time of this research, several interview participants reported that appropriate tagging, titling, and video descriptions were critical for finding relevant videos. Vague or generic tags, such as "cats," can yield a list of over 200,000 videos, which are difficult to sift through. Manipulation of video descriptions and tagging systems thus becomes crucial for video makers to regulate physical access to their videos. For example, one video maker used his YouTube name as his only tag. Unless one were a close enough friend to know this tag, it would be difficult to find his videos using the tagging system.

In addition to supporting social networks, video-sharing practices helped create new connections and develop social networks. Several interviewees said that they were not friends with their fellow video makers until they began making videos together and distinguishing their videos from other YouTube participants' work. For instance, despite living in the same dorm, one group of college students only began interacting in a qualitatively meaningful way after an incident that they considered ideal to record for YouTube. In this incident, two boys wrestled in their 
dorm's hallway. One was wearing combat gear and the other, a set of medieval armor. Several people filmed the incident, one of whom filmed it to share on YouTube, given its reputation for similar spontaneous and playful videos. The video, referred to here as Ninjas and Knights, was posted on September 30, 2006. Some of the students noted that they did not know each other well prior to the mediated incident. They further said that filming the incident for YouTube encouraged them to meet and interact with each other.

\section{Brian2:}

Yeah. We made new friends with the people who filmed us because we'd never met them before. They just came out of their rooms like, "Hey, let's film this." So one - two of the guys that were filming became new friends.

Making the video helped launch connections that did not exist prior to the mediated event. The goal was not to make a high-quality video, but rather to encode an interesting, affective experience that they could share. People who do not regularly use YouTube are often critical of the quality of videos on the site. Some participants were dismissive of the standard of other people's videos. Their objections often related to technical issues (including poor editing, lighting, sound, or some combination) or content (too many videos about people sparring). But critics fail to understand that video quality is not necessarily the determining factor in terms of how videos affect social networks. Rather, creating and circulating video affectively enacts social relationships between those who make and those who view videos. Posting the Ninja video expanded and articulated the network of people interested in participating in the video makers' experience. For students, identifying one's college in the video description and tagging system helps other students and alumni locate the video and participate in a larger community of individuals who have similar affinities.

\section{Brian1:}

... and we know a lot of other people watch [YouTube] like our friends, and it's - if we wanted to tell our friends, "Hey, come and watch this," it'd be a lot easier if we just put it on YouTube instead of sticking it in an email and waiting for the email to get there and waiting for them to open it which would take forever 'cause the file was so big. So we just put it on YouTube and go the link, sent the link to everyone, and they watched it.

Not all videos target general consumption. Some reaffirm pre-existing social networks by including material intended to appeal to shared affinities between the senders and certain receivers. Similarly, sending so-called viral videos to intimates demonstrates readiness to maintain social associations and bond with recipients. People who post criticisms, expecting a high-bandwidth, high-quality experience, fail to display affinity with the video. They effectively reject a social link to the video maker's social network members, for whom the video represents an emotional connection point. For example, in the case of the Ninja video, someone posted 
the comment, "Can I please have my five minutes and seven seconds back?" In an interview, one of the video makers said that he did not know the person who had posted this comment from either his online or offline social networks. Further, he did not appreciate the comment, nor did he feel compelled to interact with the commenter. Thus, by posting a comment that did not display affinity with the video maker, the comment discouraged the video maker from pursuing additional social contact.

Conversely, interviewees reported that people who post comments of affinity or leave thoughtful comments may prompt the video maker to respond to the poster of the comment. Video makers may react to comments by: 1) reading them; 2) posting comments in response to the comments they received on a video; 3 ) posting a comment or question on the commenter's video or channel page; 4) extending a friend request to the commenter; or 5) viewing or subscribing to the commenter's videos. Although further interaction is not guaranteed through comments, interviewees noted that these interactions were often the initial steps in broadening social connections through media circuits.

\section{Fractalized Public and Private Dynamics Reveal Different Social Networks}

Applying the fractal public/private distinction (Gal, 2002) is useful because it reveals social patterns that otherwise remain hidden. The fractal distinction between the public and private is reproduced at various levels on YouTube. At a high level, YouTube is public, especially when contrasted with home video viewing, but within YouTube, fractalized divisions occur. While some video makers heavily promote their videos to connect with many people, others tell only a few friends about their work. Moving down to the level of specific video makers, the fractalized pattern repeats. Within a single video maker's work, some videos are personal, whereas others address issues such as environmental sustainability or racism and are intended for a larger audience. ${ }^{2}$ Video makers may also have more than one YouTube account. Some celebrities reported having one account that encourages broad participation and social network linkages with fans and another account that targets circles of intimate friends.

\section{Publicly Private}

On YouTube, some participants broadcast extensive information about their identity. Moreover, they craft videos with content that is broadly appealing, and they aggressively promote and disseminate their videos. This can be considered quite public video making and viewing, because all three factors-identity information about the video maker, content relevance, and technical access to videos-are designed to be broadly appealing and widely available. On the private end of the spectrum, video makers may choose to restrict information about their identity in videos, and they may make videos with content that appeals only to a few close friends. They can also restrict access to the videos technically, by using few or cryptic tags or by invoking YouTube's "friends-only" viewing feature, according 
to which only members designated as the video maker's friends may access the video.

Other important categories of participation exist. Participants may share private experiences through video but do so in a "public way," by revealing personal identity information. This behavior may be characterized as "publicly private," in that they disclose identity information about themselves. At the same time, they use mechanisms to limit physical access to the videos or to limit understanding of their contents. The first part of this compound expression thus refers to the amount of identity information imparted by video makers. The second part refers to the available physical access to the video and to the interpretative content that may be understood only by the video maker and a few viewers.

Mechanisms that limit access may take technical and social forms. In a video referred to here as Hand Puppets, both the video's tags and content limit access to it. Theoretically, anyone can view the video and the identity information it contains. A girl's face intermittently appears on camera and the video's channel page contains identifying information. Nevertheless, only people who find it can analyze its contents. It also exhibits occasionally uneven audio, which offers another type of physical access barrier. This video was posted on July 8, 2006, and over the course of a year, it garnered only 88 views. The creator's tagging choices, which include common first names and cryptic abbreviations, complicate casual viewing access. For instance, one abbreviated tag is a reference to the religious convention that the girls attended while making the video. People who attended this convention or who are members of that religious network might use the tag to find other videos in other media circuits with the same tag. In this way, they can try to connect with other members of this social network.

Once they obtain physical access to videos, participants may have numerous interpretations, but these interpretations may not coincide with the girls' feelings about what is happening in the video or their in-jokes about the people they discuss. The video is filled with inside references and stylistics that are not intended for general YouTube viewership.

\section{Interviewer:}

What was your story idea?

\section{Allison:}

It was just basically about this guy that I met and myself, and [my friend] kept like messing up our names when we were talking about it. Like she kept calling him James instead of John, which is her brother's name. And so we decided to just change the names in the movie and such. And then we also talked about some random things that he and I had talked about on the phone and such, and yeah, it just kind of random, spur of the moment sort of things.

Anjin, a youth in his late teens, also uses cryptic tagging practices, such as using only his YouTube name. Unless one knows this name, the video's title, or words in 
the video description, it will be impossible to use the tagging and search systems to search for his videos. Only his close friends and family-whether online or offlineare likely to find his videos using the tagging system as it was implemented at the time of this writing. Unlike some other participants, he does not widely promote his videos (such as by posting comments and directing viewers to his videos). Of his nine videos, six of them received fewer than 200 views over periods ranging from five to 11 months. Even though YouTube enables global video sharing, relatively few people view his videos there. With regard to tagging practices, it should be noted that nuances in public and private access to videos are not only based on the video maker's intent. For instance, one interviewee claimed that she was simply "lazy" about putting up a lot of tags.

Certainly, viewers' and creators' interpretations may not coincide. Anjin's videos contain personal information, including his real name, the places he visits, and his and his friends' faces. In one video, Anjin and a few friends take a hike. At one point, a young man faces the camera and gives a thumbs-up sign in front of some graffiti, which is difficult to see. Anjin enlarges the graffiti in a graphic and places it next to the youth's face. The box contains the image of swastika. For many people, a swastika symbolizes Nazis and mass genocide. But as Anjin explains, the incident had a particular meaning for the small network of friends with whom he participated on the hike and with whom he shared the video.

Anjin:

And there was this graffiti there and it had a swastika. And Ben is Jewish, so we're like; ha-ha, Ben. And he's like, what. So then the kind of joke was that Ben is Jewish and he's making this thumbs up at this swastika. There's some sort of irony there. And, once again, that's just kind of our odd inbred sense of humor at work, even though it's actually pretty terrible.

The image has symbolic value to the boys who participated in the nature walk. For the youth, giving a thumbs-up sign to a swastika does not aim to transmit political information but rather creates an affinity among the friends. One of Anjin's friends later posted a comment on another video in Anjin's oeuvre. The commentNo Swastika... = (-expresses mock disappointment that the current video contained no swastika. If one has not seen the prior video, the comment's intertextual meaning is likely to be lost. Even if viewers had seen Anjin's prior video, they may not understand that the swastika is an affective symbol that refers to humor shared by a small group of friends, rather than genuine disappointment that Anjin does not place swastikas in his videos.

Why did Anjin post the video publicly, given its inside references and symbolism? Although he is aware of the friends-only viewing option, he declined to restrict physical access to his videos. For Anjin and other people interviewed, it was a matter of convenience. Although many people watch YouTube, a number do not have accounts, which are required to "friend" other participants and enable selective viewing. Notably, just as social network site participants have different interpretations 
of what constitutes a "friend" (boyd, 2006), YouTube participants apply different definitions of what constitutes a "public" video. Despite the fact that YouTube offers potential connections to a large public, some people choose to create less public videos, some of which are not available or interesting to people beyond a few close friends.

\section{Anjin:}

...And like I said, I don't really feel too bad about [the swastika video] because I don't, like, display it super publicly. I guess people could stumble onto it randomly but nobody has given me a hard time about it yet.

Within Anjin's YouTube oeuvre, fractalized gradations between public and private videos exist. Although he does not consider most of his videos "super public," since they contain inside references and few people actually watch them on YouTube, some of his videos are "more public" than others. For example, on a martial arts video he used tags that included the name of the martial art. Over a seven-month period, the video garnered over 2,000 views, which is far more than Anjin's other videos. The martial art is practiced around the world and thus has potentially broad social relevance to other dispersed practitioners. One person posted the comment, "Very cool...if you guys are ever in New York, make sure to stop by our branch. =) Best wishes." This poster simultaneously invites Anjin into his social network and expresses interest in joining Anjin's network based on common interest in the video's content.

\section{Privately Public}

YouTube participation may take another hybrid form. ${ }^{3}$ Being "privately public" means making connections with many other people, while being relatively private with regard to sharing identity information. Participants in this category conceal certain aspects of their identity, while expanding their friend and subscriber base and making videos with widely accessible content. Privately public individuals who were interviewed included YouTube celebrities and non-famous participants who wished to retain some anonymity. For instance, one person did not want his identity revealed, lest it compromise professional credibility with clients and co-workers. Other people cited concerns about safety and the desire to avoid stalkers.

One privately public video, which is referred to here as Vlad The Impaler, showed a mask-wearing monster. "Vlad's" menacing speech echoes the sentiments of other participants who wish to interact with many people, but in a way that conceals identifying information. The video announces a series of videos that he and his friends intend to make. In this video, Vlad outlines the level of identity that people should expect.

\section{Vlad:}

We have a strict rule [governing] our society that there are some things that should never be seen, should never be known, [which is] more for our protection than yours. If people knew that we were doing such things, [we] 
would be punished, so you'll never know our real names or our real faces but you will know our entertainment.

In a chat interview, CT, a youth in his mid-teens, said that he created this character with select friends as a secret joke. Although CT is in the costume, another friend provided a narrative voice over, in which his voice was modulated to sound lower. CT made the video after another friend (RJ) “jokingly" told him that he didn't need CT's help to make videos. RJ implied that CT's contribution was technically lacking. In response, CT and some other friends created the "Vlad the Impaler" character. CT's goal with the "Vlad" films was to become quite popular on YouTube and then reveal himself to his friend RJ, so that RJ would know that he had misjudged CT's talent.

CT:

the first vid was to make it seem like we had no clu what we were doing and $\mathrm{i}$ wanted it to [build] up... and when the time came if we had a lot more views than RJ we would [unveil] our selves, but we havent been able to make any videos for them

Interviewer:

Wow!

CT:

we were going to make them in a way where we wouldnt have to show our faces

Interviewer:

Why [wouldn't] you show your faces?

CT:

well so nobody on youtube, or RJ would [know]

just to prove him wrong

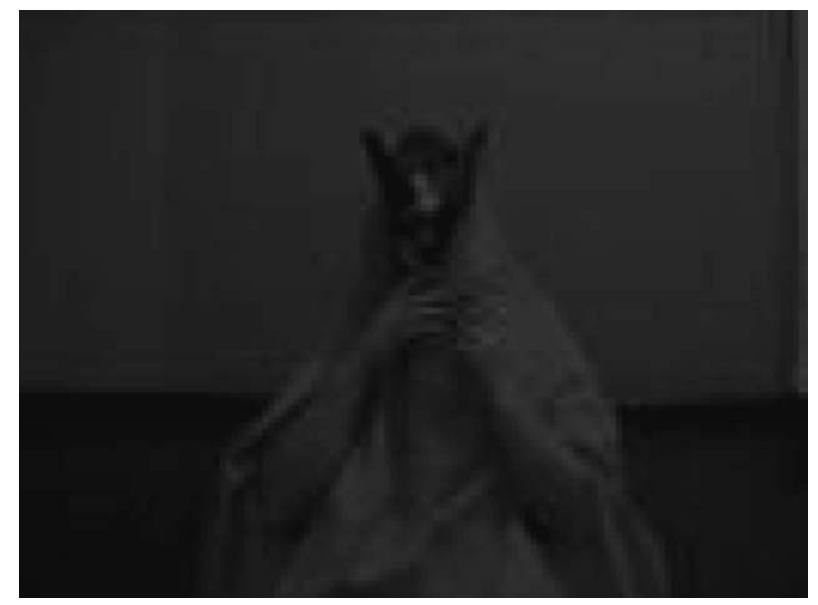

Figure 1 "Vlad the Impaler" 


\section{Interviewer: ...}

It is rather [surprising] to me that RJ did not notice that video. I scanned through [Vlad's] subscriber list and it is not that long.

CT:

well one day he had seen it

and then he showed it to me that day because we had subscribed to him (he always checks that) and was like hey [CT] look at this noob ${ }^{4}$

$\mathrm{i}$ had to comment on the cool [lighting] effect

CT uses video in a way that articulates two separate social networks to which he belongs. The first includes his friend and video-making partner, RJ. The second includes a group of friends from which RJ is excluded. RJ was not invited to create the "Vlad the Impaler" video, because he had "insulted" CT. Even though the video is "public," in the sense that anyone using YouTube, including RJ, can view it, RJ did not recognize his own friend in the video and did not associate CT with Vlad. Despite being a close friend of CT's, RJ cannot access the symbolic meaning of the video that refers to conflict between CT and RJ. In this sense, although public, the "Vlad" video was not interpretable in the same way by all who viewed it. Again, there appears to be a fractalization of the public and private in terms of how CT presents himself in different media circuits that support social connections in varyingly public and private ways. When he makes videos with RJ, he reveals his face, name, and location. Yet when he made the Vlad film, he withheld that information and sought more "privately public" connections to new fans. It should be noted that CT's intentions do not guarantee identification privacy; RJ's role in failing to recognize CT was critical for CT's ruse to work.

Some well-known YouTubers also exhibit this type of privately public participation. A further fractalization of relative public and private behavior appears across different participants within this category in terms of their levels of identity revelation. Examples include MysteryGuitarMan (MGM) and MadV. MGM discloses

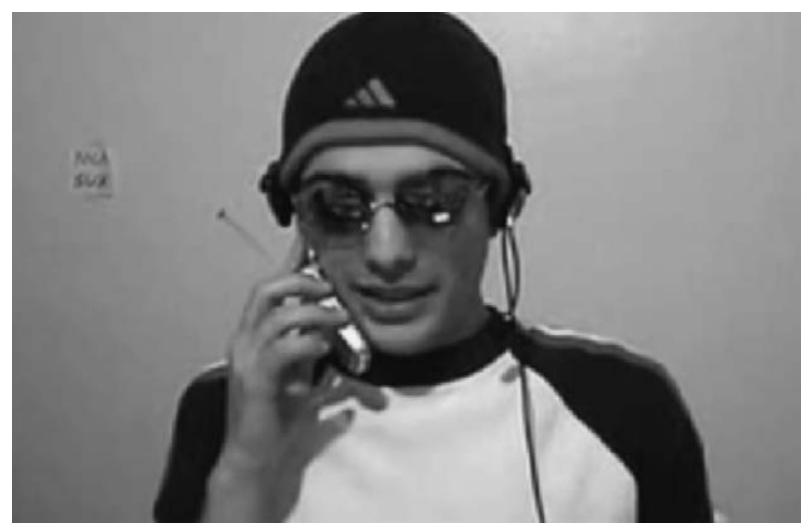

Figure 2 MysteryGuitarMan 
more personal information than does MadV. For instance, MGM speaks and shows himself on camera, albeit usually behind glasses and often wearing a hat. ${ }^{5}$ In contrast, MadV wears a Guy Fawkes ${ }^{6}$ mask, does not disclose much personal information about himself, and never speaks. ${ }^{7}$

Although MadV's participation is public, in that a large number of people view his work and have a connection to him (as a YouTube "friend" or subscriber), the person behind the persona does not disclose identity details such as name, location, occupation, age, and gender. ${ }^{8} \mathrm{MadV}$ has maintained relative anonymity, although he said that this is becoming "trickier" as he attains greater popularity and participates in a widening social network on YouTube. MadV interacts with fans while maintaining a mysterious persona in a Guy Fawkes mask, a symbol that appears in many art works such as the vigilante character named "V" in the dystopic film, $V$ for Vendetta. MadV said that he did not adopt the mask to show alliance with this $\mathrm{V}$ character. Indeed, MadV does not allow posted comments that suggest that he wishes to overthrow a government. People attempting to enter his YouTube media circuit using these comments are barred from entry both technically and socially, since MadV also deletes such comments from his YouTube pages. These types of negotiations determine whom MadV will allow into his social network.

People may friend or subscribe to MadV because his videos, such as One World, are broadly appealing and popular. People may assume that MadV is aligned with the "One World" movement, ${ }^{9}$ which promotes a more just global society in which people can access information and make connections worldwide. Instead, MadV said he wished to raise global awareness, a topic that also has wide appeal and interests many. In this video, MadV invites others to "make a statement" and to "make a difference." He holds up his hand to the camera. On it is written the phrase, "One World." Many viewers joined this media circuit by posting videos in which they wrote special messages on their hands (thus becoming video makers as well as viewers). Within an eight-month span, One World garnered more than one million views and over 2,000 video responses. At one point, it also held the honor of being the "most responded to video of all time on YouTube."

MadV encourages broad participation, albeit anonymously, by making videos that potentially concern many people and adopting liberal friending practices. Although MadV connects with many people, he nevertheless allows only certain kinds of comments to be posted on his videos. By refusing to post comments or videos from others who try to guess or knowingly reveal his identity, MadV tries to maintain a degree of privately public participation. He writes people who make such attempts at disclosure out of his YouTube media circuit. By placing a comment of affinity to MadV's work, a supporter can write him- or herself into a social network in which MadV is the center by showing how MadV is relevant to them. The way in which a participant responds to other participants illustrates different relationship patterns. Examining these patterns reveal particular media circuit topologies. For example, MadV said in an interview that he does not subscribe to other people's channels or initiate friend requests. In this sense, the media circuit topology that 
MadV supports is one in which he is the center of a directed social network in which the fans watch and comment on his videos, but he does not engage in these same practices toward fans. His practices are quite different from those that other interviewees reported, in which small, close groups of friends post and watch videos intended for consumption by a limited group. This and the other examples presented above illustrate how by examining participants' choices with regard to video sharing practices, processes of social network maintenance, delineation, and negotiation are revealed.

\section{Discussion}

This research suggests that for many participants, profile linkages are not the only or even the primary way of supporting a social network through YouTube. A more common practice among the interviewees was posting videos that friends and family could see and respond to. Posting comments also enabled people to express feelings of affinity for the video or the video makers. Media circuits are useful for understanding how social networks are created, maintained, and negotiated in public arenas such as on YouTube. Sharing and commenting on videos helped users maintain connections with their friends and relatives at a distance, and such behaviors facilitated membership negotiation within social networks. Interviewees reported that intelligent commentary on a video could stimulate closer social connections, if the video maker continues to communicate with and interact with the poster of the commentary.

Why do networks fractalize in ways that rupture yet maintain relative public and private social relations? Nissenbaum (2004) argues that some privacy is required for individuals to self-actualize. Privacy is arguably necessary for advancing the self and protecting the integrity of relationships. Having insulation against outside scrutiny is important for experimenting with aspects of the self without fear of retribution. For instance, as part of CT's "privately public behavior," he cloaked himself in a character in order to develop video skills, garner a fan base, and then reveal himself, once successful, to his old friend RJ. Different kinds of relationships require distinctive levels of protection from outside parties; these are manifested in varied levels of publicness and privacy in video making and sharing.

The question also arises: Why do people engage in "publicly private" behavior? This study identified two main reasons. First, the technical options for delineating media circuits as implemented at the time of the research had drawbacks. Many interviewees wished to share media with particular friends or family members but did not want to use the friends-only viewing option, because it required viewers to have an account. Nevertheless, YouTube was a convenient way to circulate videos with dispersed friends and relatives whom they knew watched YouTube. Some interviewees responded to the problem of sharing in public by using limited tagging, such that only people in the social network who knew the tags-which included cryptic references such as the video maker's YouTube name-would be able to use to locate participants' videos. 
In addition, some interviewees used their view counts and comment systems as a way of gauging viewership, determining that their videos were not "super public" if they did not garner much response. Just as prior research on blogging demonstrated (Nardi, Schiano, \& Gumbrecht, 2004; Viégas, 2005), a few interviewees were indifferent to being watched. Further, they did not express awareness about how their material could be accessed in ways outside their control. For instance, after the purchase of YouTube, Google enabled its search engine to return results from general searches that included YouTube videos. Such a feature widens video makers' exposure to being viewed, if they use tags that people searching Google also use to find material. YouTube also lists a number of "related" videos next to the current video being watched. If YouTube places a video maker's video on a "related list," the video may get more exposure than the video maker anticipated. Video source code can also be placed on profiles of other social network sites, allowing people to access videos from YouTube.

This article reveals that what constitutes how "public" a media circuit is varies, depending on participants' display of information about themselves and the content that they produce. For instance, MadV kept his identity guarded and reported that he does not know most people in his YouTube media circuit offline, but he encourages broad online viewership and friendships in a way that is not "mutual" with his fans. Posted videos and related comments create media circuits that take on a variety of different forms according to the relationships that they reflect. In MadV's case, fans watch and comment on his videos, but the social trajectory only moves in one direction, since MadV does not subscribe to other people's videos nor initiate friend requests. Different media circuit types reflect different interaction dynamics.

Future studies could examine different types of media exchange to see what they reveal about underlying social relationships. The social connections in a group in which media are circulating among a small number of people may differ from those in a group in which media are distributed only in one direction, as is the case between certain YouTube celebrities and their fans. A small private network may more interactively exchange media in bi-directional exchanges than a fan-centric media circuit with a YouTube star. Viewing the media exchange trajectories in different media circuits may thus shed light on other types of media-supported social relationships.

The analysis has shown that the public and private fractalize in complex ways in video making and sharing on YouTube. It also supports previous scholarship that claims that watching media is not merely a passive exercise, but rather that film or video viewing in general involves active interpretations that shape reception of media messages (Friedman, 2006). On YouTube, frequent interaction between video makers and viewers is a core component of participation on the site. Viewers and commenters are often themselves video makers, who comment with the strategic intent of forming social relationships with others who will support their work. Some interviewees reported that their attempts to be "friends" with popular YouTube stars 
were lost in large, mediated, social networks. In the context of liberal friending practices, discourse through comments and video responses provides another way for participants to establish meaningful social connections.

\section{Conclusion}

This article demonstrated how YouTube participants used both technical and symbolic mechanisms to attempt to delineate different social networks. It proposed new categories of nuanced behavior types that are neither strictly public nor strictly private. Moreover, it demonstrated that parts of social networks, as supported by media circuits, can be examined to shed light on the dynamics of social network creation, maintenance, and negotiation. Beyond profile-based friendship connections, the analysis showed how video sharing can become an important way for participants to negotiate membership in social networks.

These findings also have design implications. As social groups and professional organizations increasingly supplement their websites with social network site components, it is important to be alert to fractalization touch points, where greater amounts of publicity or privacy may be required to meet different individuals' and groups' social needs. Technical features that provide participants more customization and control in creating public and private interactions could help to optimize social network site usage.

As intentional and unintentional surveillance becomes more commonplace in contemporary society, people will likely continue to seek ways to carve out privacy in highly visible media environments. While corporations and institutions may require additional information sharing and employee monitoring on the company Website, the present analysis suggests that some participants will nevertheless manipulate public systems in ways that preserve, in a fractalized pattern, different desired levels of informational and behavioral publicity and privacy. Analyzing micro-processes of networking through video sharing is one way to understand how social groups strive to protect varied levels of privacy amid increasing public scrutiny.

\section{Notes}

1 On YouTube channel pages, participants can display friend and subscription links or withhold them from view, even from other YouTube friends. This contrasts to Donath and boyd's (2004) finding that friendship links are assumed by many participants to be "mutual" and "public" on social network sites. Subscriptions mean that when a new video is posted, all the video maker's subscribers are alerted through email about it. Some interviewees had difficulty distinguishing the social difference between accepting a friend request and subscribing to their videos.

2 The claim here is not that all viewers interested in racism or other subjects will actually view a particular video, but rather, as Weintraub (1997) points out, that some subjects are considered more public than others. What scholars have characterized as relatively 
more public issues are those that concern a larger collective versus, for example, gossip that involves an event that relatively few people know or care about.

3 The two intermediate forms ("publicly private" and "privately public') discussed here are not the only ones. However, these forms emerged as particularly salient in the dataset used in this study.

4 A "noob" (short for "newbie") is a person who is new to a social group, typically an online environment. The term is often used in a derogatory way to characterize someone who is unfamiliar with the technical and social aspects of a particular online community or activity.

5 A sense for his level of participation can be gotten from his channel page: http:// www.youtube.com/profile?user=mysteryguitarman. Retrieved October 29, 2007.

6 For more information about Guy Fawkes, see "The Gunpowder Plot" (2006).

7 MadV's channel page can be accessed at: http://www.youtube.com/profile?user=madv. Retrieved October 29, 2007.

8 Here I follow his fans' convention and refer to him as "he."

9 http://us.oneworld.net/. Retrieved October 29, 2007.

\section{References}

Al-Saggaf, Y. (2006). The online public sphere in the Arab world: The war in Iraq on the Arabiya Website. Journal of Computer-Mediated Communication, 12(1), article 16. Retrieved July 1, 2007 from http://jcmc.indiana.edu/vol12/issue1/al-saggaf.html

Barnes, S. B. (2006). A privacy paradox: Social networking in the United States. First Monday, 11(9). Retrieved July 1, 2007 from http://www.firstmonday.org/issues/issue11_9/barnes/ index.html

Baym, N. (2000). Tune in Log On: Soaps, Fandom, and Online Community. Thousand Oaks, $\mathrm{CA}$ and London: Sage.

boyd, d. (2006). Friends, Friendsters, and Top 8: Writing community into being on social network sites. First Monday, 11(12). Retrieved February 28, 2007 from http:// www.firstmonday.org/issues/issue11_12/boyd/

Donath, J., \& boyd, d. (2004). Public displays of connection. BT Technology Journal, 22(4), 71-82.

Ellison, N. B., Steinfield, C., \& Lampe, C. (2007). The benefits of Facebook "friends:" Social capital and college students' use of online social network sites. Journal of Computer-Mediated Communication, 12(4), article 1. Retrieved August 28, 2007 from http://jcmc.indiana.edu/vol12/issue4/ellison.html

Feder, J. (1988). Fractals. New York and London: Plenum Press.

Friedman, S. L. (2006). Watching twin bracelets in China: The role of spectatorship and identification in an ethnographic analysis of film reception. Cultural Anthropology, 21(4), 603-632.

Gal, S. (2002). A semiotics of the public/private distinction. Differences: A Journal of Feminist Cultural Studies, 13(1), 77-95.

Gross, R., \& Acquisti, A. (2005). Information revelation and privacy in online social networks. Proceedings of WPES'05 (pp. 71-80). Alexandria, VA: ACM.

“The gunpowder plot." (2006). Retrieved February 28, 2007 from http://www.parliament.uk/ documents/upload/g08.pdf 
Horst, H. A., \& Miller, D. (2006). The Cell Phone: An Anthropology of Communication. Oxford, UK and New York: Berg.

Ito, M., \& D. Okabe (2005). Technosocial situations: Emergent structurings of mobile email use. In M. Ito, D., Okabe, \& M. Matsuda (Eds.), Personal, Portable, Pedestrian: Mobile Phones in Japanese Life. Cambridge, MA: MIT Press.

Kendall, L. (2002). Hanging Out in the Virtual Pub: Identity, Masculinities, and Relationships Online. Davis: University of California Press.

Lange, P. G. (2007 March). Commenting on comments: Investigating responses to antagonism on YouTube. Paper presented at the Annual Conference of the Society for Applied Anthropology. Retrieved August 29, 2007 from http://sfaapodcasts.files. wordpress.com/2007/04/update-apr-17-lange-sfaa-paper-2007.pdf

Nardi, B. A. (2005). Beyond bandwidth: Dimensions of connection in interpersonal communication. Computer-Supported Cooperative Work, 14, 91-130.

Nardi, B., Schiano, D., \& Gumbrecht, M. (2004). Blogging as social activity, or, would you let 900 million people read your diary? Proceedings of Computer-Supported Cooperative Work 2004. New York: ACM Press.

Nissenbaum, H. (2004). Privacy as contextual integrity. Washington Law Review, 79(1), $101-158$.

Rouse, R. (1991). Mexican migration and the social space of postmodernism. Diaspora, 1(1), $8-24$.

Sandvig, C. (2006). The Internet at play: Child users of public Internet connections. Journal of Computer-Mediated Communication, 11(4), article 3. Retrieved July 1, 2007 from http://jcmc.indiana.edu/vol11/issue4/sandvig.html

Schoeman, F. (1984). Philosophical Dimensions of Privacy. Cambridge, UK: Cambridge University Press.

Sheehan, K. B. (2002). Toward a typology of Internet users and online privacy concerns. The Information Society, 18(1), 21-32.

Viégas, F. B. (2005). Bloggers' expectations of privacy and accountability: An initial survey. Journal of Computer-Mediated Communication, 10(3), article 12. Retrieved August 20, 2007 from http://jcmc.indiana.edu/vol10/issue3/viegas.html

Weintraub, J. (1997). The theory and politics of the public/private distinction. In

J. Weintraub \& K. Kumar (Eds.), Public and Private in Thought and Practice (pp. 1-42). Chicago and London: University of Chicago Press.

Weintraub, J., \& K. Kumar, (Eds.) (1997). Public and Private in Thought and Practice. Chicago and London: University of Chicago Press.

Wellman, B. (1996). Are personal communities local? A Dumptarian reconsideration. Social Networks, 18(4), 347-354.

\section{About the Author}

Patricia Lange [plange@cinema.usc.edu] is a postdoctoral fellow in the School of Cinematic Arts at the University of Southern California. Her research explores issues of technical identity performance, identity in online environments such as video sharing sites, emotions in online encounters, and bodily experience of place.

Address: 746 East Adams Boulevard, Los Angeles, CA 90089, USA 